Elżbieta Sadoch, M.A. https:/ / orcid.org/0000-0002-0997-8473

Faculty of Humanities

Cardinal Stefan Wyszyński University

in Warsaw

\title{
Tesori di arte sacra a Venezia e Padova nelle descrizioni dei viaggiatori polacchi del XVIII secolo
}

\author{
Skarby sztuki sakralnej w Wenecji i Padwie \\ w opisach polskich podróżników z XVIII wieku
}

https:// doi.org/10.34766/fetr.v48i4.950

\begin{abstract}
In the 18th century, Italian sanctuaries played an important religious and cultural role, especially in Venice and Padua. They were visited by Polish travelers during their trips around Europe, such as: diplomatic missions, pilgrimages, educational or tourist trips. Impressions from visiting these places they wrote down in their diaries and journals. Reading the reports from the expeditions provides valuable insights on the mentality, education, as well as the religious and aesthetic experiences of eighteenth-century adventurers. The article aims to present the ways of describing collections of sacred art by Polish travelers from the 18th century. The analysis of their accounts, especially the fragments concerning the sanctuaries in Venice and Padua, will serve to present the literary covenants used by Polish travelers. It should also answer the questions which tendencies dominated in the travel literature of that time, what phrases and formulations were used, and what items were paid special attention to.
\end{abstract}

Keywords: polish travelers, travel reports, sanctuaries, church collections

Abstrakt: W XVIII wieku ważną rolę religijną i kulturową pełniły włoskie sanktuaria, zwłaszcza w Wenecji i Padwie. Odwiedzali je polscy podróżnicy w trakcie swoich wypraw po Europie, takich jak: misje dyplomatyczne, pielgrzymki, podróże edukacyjne bądź turystyczne. Wrażenia ze zwiedzania tych miejsc spisali w swoich pamiętnikach i dziennikach. Lektura relacji z wypraw dostarcza cennych spostrzeżeń na temat mentalności, wykształcenia, a także przeżyć religijnych i estetycznych osiemnastowiecznych wojażerów. Artykuł ma na celu przybliżyć sposoby opisywania zbiorów sztuki sakralnej przez polskich podróżników z XVIII wieku. Analiza ich przekazów, przede wszystkim fragmentów dotyczących sanktuariów w Wenecji i Padwie, posłuży do przedstawienia konwencji literackich z jakich korzystali polscy podróżnicy. Powinna również udzielić odpowiedzi na pytania jakie tendencje dominowały w ówczesnej literaturze podróżniczej, jakich zwrotów i sformułować używano, a także na jakie przedmioty zwracano szczególną uwagę.

Słowa kluczowe: polscy podróżnicy, relacje z podróży, sanktuaria, zbiory kościelne

\begin{abstract}
Nel XVIII secolo santuari italiani svolgevano un importante ruolo religioso e culturale, soprattutto a Venezia e Padova. Sono stati visitati dai viaggiatori polacchi durante i loro viaggi in giro per l'Europa, come: missioni diplomatiche, pellegrinaggi, viaggi d'istruzione o turistici. Impressioni dalla visita di questi luoghi hanno scritto nei loro memorie e diari. La lettura dei resoconti di viaggi fornisce preziosi spunti sulla mentalità, l'educazione, nonché le esperienze religiose ed estetiche dei viaggiatori del Settecento. Nell'articolo si tenta di presentare le modalità di descrizione delle collezioni di arte sacra da parte dei viaggiatori polacchi del XVIII secolo. L'analisi delle loro testimonianze scritte, in particolare frammenti sui santuari di Venezia e Padova, serviranno per presentare le convenzioni letterarie adoperate dai viaggiatori polacchi. Dovrebbe rispondere anche alle questioni su
\end{abstract}


quali tendenze dominavano nella letteratura di viaggio di quel tempo, quali frasi venivano usate e a quali oggetti veniva prestata una particolare attenzione.

Parole chiavi: viaggiatori polacchi, diari di viaggio, santuari, collezioni ecclesiastiche

\section{Introduzione}

I temi delle scritture di viaggio polacche del XVIII secolo furono affrontati nelle opere dell'ambito degli studi letterari, storici e della storia dell'arte. Furono introdotte anche le caratteristiche dei resoconti delle spedizioni all'estero, l'atteggiamento del soggetto parlante, nonché i metodi per presentazioni della strada (Abramowska, 1978; Dziechcińska, 1967, 1988; Horolets, 2012; Kaczmarek, 1962; Niedzielski, 1966; Sajkowski, 1964; Trzynadlowski, 1961; Witosz, 2007). Molta attenzione è stata dedicata ai contatti, alle rotte e alle destinazioni italopolacche (Barycz, 1965; Biliński, 1968; Brahmer, 1939, 1980; Chachaj, 1998; Kot, 1987; Loret, 1930; Mączak, 2001; Rok, 1992; Sajkowski, 1973). Sono state affrontate la formazione e le preferenze degli autori delle relazioni (Bratun, 2002; Dziechcińska, 2003; Gad, 2013; Kicińska, 2014; Loret, 1929; Popiołek, 2014; Żołądź-Strzelczyk, 1998, 2011). Si è scritto anche sulle percezioni dei pellegrini della terra italiana, delle città ovalpine e degli oggetti d'arte italiani (Backvis, 1975; Dziechcińska, 1991, 1992, 2011; Grzybowski, 1998; Kowalczyk, 2004, 2005; Norkowska, 2020; Rok, 2014; Wrześniak, 2010a, 2013; Wyrzykowska, 2007, 2012). Finora però non sono state studiate testimonianze sui monumenti veneziani e padovani funzionanti come tesori d'arte sacra nella percezione dei viaggiatori. Pertanto, questo articolo si propone di completare la conoscenza dei resoconti polacchi dei viaggi italiani nel XVIII secolo.

L'obiettivo dello studio è un tentativo di definire la strategia di presentazione dei santuari veneti inseriti nelle relazioni settecentesche sul pellegrinaggio. Verrà effettuata un'analisi comparativa delle opere selezionate, in particolare dei loro frammenti contenenti le impressioni dei viaggiatori della visita alle principali chiese - S. Marco a Venezia e due basiliche a Padova: S. Antonio e S. Giustina. Saranno presi in considerazione testi scritti nel tardo barocco e nell'illuminismo polacco. In primo luogo, verranno discussi messaggi rappresentativi, seguiti da convenzioni letterarie utilizzate dai viaggiatori polacchi. Queste riflessioni verranno utilizzate per mostrare schemi descrittivi e topoi duplicati negli scritti studiati. Riveleranno anche l'importanza delle collezioni ecclesiastiche nel plasmare la sensibilità estetica di potenti signori, sia artisti che esperti d'arte, oltre che dilettanti.

La base di partenza per le questioni discusse sono documenti commemorativi, ossia le opere di natura autobiografica - diari e memorie. Questi testi sono classificati come strutture a forma di diario (Sajkowski, 1964), le memorie in prosa (Cieński, 1992; Dziechcińska, 1993), gli scritti autobiografici (Czermińska, 2000), o letteratura della cronistoria personale (Szulakiewicz, 2013; Zimand, 1990). A volte vengono indicati come rapporti di viaggio (Iwanowska, 1990) o di pelegrinaggio (Kaczmarek, 1962). Va aggiunto 
che gli scritti in questione contengono fatti ed eventi relativi ad un viaggio autenticamente compiuto. C'è un narratore che informa sugli oggetti visitati. Tuttavia, differiscono nel modo di prendere appunti. Questi includono registrazioni personali fatte durante il viaggio, resoconti scritti in memoria dopo il ritorno nel paese, nonché testi preparati per la stampa.

\section{Rapporti polacchi sulla visita ai santuari di Venezia e Padova nel XVIII} secolo

I rappresentanti dell'élite sociale che annotavano le impressioni della loro permanenza nei centri di culto transalpini erano rappresentanti della élite sociale, in particolare: clero e nobili. Questi includevano pellegrini che visitavano i centri religiosi per ottenere un'indulgenza o per vedere un dipinto miracoloso. Un gruppo significativo formavano i monaci che andavano ai capitoli generali e sacerdoti che si occupavano di questioni amministrative nella Santa Sede (Loret, 1930; Rok, 2014). Artisti e amanti dell'arte visitavano i santuari, per poter ammirare i famosi monumenti e le opere d'arte antiche custodite sul suolo italiano (Mączak, 2001; Wrześniak, 2011, 2013; Wyrzykowska, 2012). Tra i viaggiatori vi erano anche gli aristocratici impegnati a percorrere il grand tour, seguendo la moda d'allora. Loro interessi spaziavano tra eventi culturali e opere d'arte (Kowalczyk, 2019; Roćko, 2014; Wrześniak, 2013). Alla luce di questi argomenti, va ricordato che gli escursionisti polacchi sceglievano percorsi noti, compresi quelli che attraversano la Slesia, la Moravia e l'Austria. Un'altro tragitto passava per Vienna, la Stiria e Lubiana. Invece la terza rotta andava da Vienna attraverso Graz e Lubiana verso Triester, per poi dirigersi nell'Italia attraverso il mar Adriatico. I viaggiatori polacchi visitavano luoghi simili. Sul territorio Veneto di solito ammiravano Venezia e Padova (Kowalczyk, 2005, p. 107; Wrześniak, 2011, p. 13).

Visitatori polacchi lasciarono molti resoconti dei pellegrinaggi nel XVIII secolo. Gli scritti erano di carattere informativo e documentario e usati perlopiù per commemorare la spedizione straniera, oltre a luoghi e oggetti famosi. La maggior parte delle note è rimasta in forma manoscritta. I registri di viaggio facevano parte dei registri commemorativi, insieme ai raptularia, calendari e appunti di viaggio (cf. Dziechcińska, 1999, p. 14; Iwanowska 1990, p. 124; Mączak 2001, p. 10). I pellegrini spesso facevano selezione e ordinamento degli eventi a cui avevano assistito o osservato. Nei testi ricorrevano alla figura di un viaggiatore-narratore che ricreava il corso del viaggio. In tal modo citavano in prima persona i posti in cui soggiornavano, come i santuari veneziani e padovani. Questi componimenti prendevano vari titoli che includevano seguenti nomi - diario di viaggio, diarium, descrizione del viaggio, percorso, itinerario o anche: journal de voyage, mon voyage en Italie (cf. Kowalczyk, 2005, p. 80).

Vale la pena di ricordare che gli scritti in questione sono stati composti in due epoche dela storia polacca: nel periodo sassone e in quello di re Stanislao. Pertanto, essi sorgevano 
sotto l'influenza di enormi cambiamenti nella cultura, nell'arte e nella letteratura. All'inizio del XVIII secolo, viaggiatori creavano calendari e registri geografici e diari che facevano riferimento ai libri domestici, sfruttando convenzioni e motivi tradizionali. Di tanto in tanto condividevano le loro impressioni sui tesori dell'arte sacra. Nella seconda metà del XVIII secolo, gli autori di resoconti iniziarono ad allontanarsi dalle tendenze costanti nella letteratura di viaggio. Si cominciò a prendere gli appunti più liberamente e aggiungendo ampie descrizioni dei templi. Sempre più spesso si era disposti a documentare le preferenze personali e le valutazioni estetiche. A volte giudizi erano molto critici sull'architettura delle chiese, così come sui metodi per rendere accessibili i depositi dei templi (cf. Dziechcińska, 1999, pp. 50-51; Wrześniak, 2011, pp. 15-16).

Per la questione discussa, una preziosa fonte di epoca sassone rappresentano i documenti di Krzysztof Zawisza e Felicjan Junosza Piaskowski. I loro rapporti sono stati inclusi come capitoli distinti nelle memorie. Krzysztof Zawisza (1666-1721) fu un nobile con lo stemma del Cigno, un eccezionale oratore e politico, nonché un voivoda di Minsk. Nel 1700 si recò a Roma per ottenere un'indulgenza (Kowalczyk, 2005, p. 81; Wrześniak, 2010a, pp. 207-214; Roćko, 2001, pp. 313-314). Un altro viaggiatore, Felicjan Junosza Piaskowski (1690-1741) veniva da una famiglia nobile che si stabilì in Volinia. Ha servito alla corte del magnate Jerzy Dominik Lubomirski. Negli anni 1717-1720 percorse il suolo italiano e francese per completare la sua educazione (Chachaj, 2001, pp. 343-360; Kowalczyk, 2005, p. 89; Wrześniak, 2010d, pp. 95-96, 2013, p. 90). Entrambi i pellegrini presentarono l'andamento della spedizione in modo simile, utilizzando il sistema cronologico-geografico. Inormarono sulle difficoltà di viaggio, percorsi, città e templi visitati. Descrivevano i più importanti santuari di Venezia e Padova, nonché le reliquie e gli oggetti di pregio nelle basiliche.

Anche da parte del clero giunsero resoconti dei viaggi in Italia: Symforian Arakiełowicz, Remigiusz Zawadzki e Stanisław Kleczewski. Appartenevano all'Ordine Francescano Riformato. Furono anche emissari ai capitoli generali dei Frati Minori Osservanti a Roma. Symforian Arakiełowicz (1678-1742) aveva radici armene. Si laureò in filosofia e teologia, nel $1703 \mathrm{fu}$ ordinato sacerdote e nel 1721 divenne guardiano a Leopoli, poi custode e maestro dei novizi a Sandomierz. Nel 1723 partì per le deliberazioni dell'Ordine presso la Santa Sede come rappresentante della Provincia Małopolska (Kowalczyk, 2003, p. 139, 2005, p. 81). Remigiusz Zawadzki (1703-1775) ricevette un'educazione filosofica e teologica, divenne insegnante di teologia e maestro dei novizi, e poi custode a Varsavia. Nell'ordine ricoprì i seguenti incarichi: definitore, provinciale e custode. Nell'anno giubilare 1750 rappresentò la Provincia di Wielkopolska al Capitolo Generale dell'Ordine nella Città Eterna (Kurzyński, 2018, pp. 95-97; Kowalczyk 2005, p. 68). D'altra parte, Stanisław Kleczewski (1714-1776) fu un linguista, scrittore, storico e filosofo polacco. Nell'ordine ricoprì la carica di custode e provinciale. Nel 1750 partecipò anche alle ordinanze di Roma (Kurzyński, 2018, p. 95; Kowalczyk 2005, p. 68). Durante il viaggio, i 
sopraddetti sacerdoti tenevano appunti che dovevano dare indizi agli altri confratelli dell'ordine. Per questo motivo, diedero molte informazioni pratiche, come le distanze tra i centri religiosi, i trasporti, le usanze e i servizi locali. Descrissero anche l'architettura e l'arredamento di famose basiliche - S. Marco a Venezia e S. Antonio e S. Giustina a Padova, menzionando pure gli oggetti di valore raccolti nei santuari.

Bisogna riportare anche messaggi trasmessi da Juwenalis Charkiewicz e Maciej Borkowski. Diari di questi sacerdoti presentano molte caratteristiche dei documenti tradizionali dell'epoca sassone, sebbene furono creati nella seconda metà del XVIII secolo. Juwenalis Charkiewicz (1720-1788) fu Superiore Provinciale Lituano dei Bernardini. Nel 1768 partecipò al capitolo generale dell'Ordine dei Frati Minori a Valencia. Tornato in Lituania, visitò famosi centri di pellegrinaggio (Kurzyński, 2016, p. 108). Poco si sa di Maciej Borkowski. È possibile che appartenesse all'Ordine dei Francescani Riformati. Nel 1775 si recò presso la Santa Sede per ottenere il permesso di lasciare l'ordine e trasferirsi al ministero nella diocesi di Varsavia (Grzybowski, 1995, pp. 95-96). Durante il loro viaggio all'estero, entrambi i pellegrini annotavano continuamente eventi, luoghi e oggetti. Hanno lasciato notizie brevi e attendibili sui santuari di Venezia e Padova. Ammirarono le dimensioni e la ricchezza dei templi e il gran numero di reliquie ivi custodite.

Gli studiosi dell'era illuminista - August Fryderyk Moszyński e Stanisław Staszic trasferirono le loro impressioni dalle visite nei centri religiosi sulle pagine dei diari. Gli appunti dei loro pellegrinaggi contengono molte osservazioni personali relative a oggetti di culto: reliquie e immagini di santi. August Fryderyk Moszyński (1731-1786) proveniva da un'eccellente famiglia dello stemma di Nałęcz. Aveva una vasta gamma di interessi, come la politica, l'economia, l'architettura e la progettazione di giardini. Nel 1784-1786 visitò la Francia, l'Inghilterra e l'Italia (Kostkiewiczowa, 1988, pp. 203-216; Kowalczyk, 2005, p. 82; Łukasiewicz, 2021, p. 124; Wrześniak, 2013, pp. 135-136). D'altra parte, Stanisław Staszic (1755-1826) era un ecclesiastico, un eccezionale filosofo, naturalista, geografo, scrittore e coautore di riforme statali. Negli anni 1790-1791 fece un viaggio in Italia come mentore dei figli di Andrzej Zamoyski (Sajkowski, 1973, pp. 117-123; Kowalczyk, 2005, p. 82; Wrześniak, 2010c, p. 131, 2013, p. 166-173). I suddetti viaggiatori notarono edifici religiosi a Venezia e a Padova. Prestavano attenzione principalmente all'architettura dei templi, nonché ai dipinti di artisti famosi, spesso integrando le descrizioni con commenti e giudizi estetici (cf. Mączak, 2001, p. 169; Łukasiewicz, 2021, pp. 129-130; Wrześniak, 2010c, pp. 133-136, 2012, pp. 211222).

Tra le relazioni di viaggio settecentesche spiccano diari femminili - Teofila Konstancja Morawska de domo Radziwiłł e Katarzyna Plater de domo Sosnowska. Le due nobildonne polacche hanno partecipato a un grand tour, ossia, "un viaggio di carattere estetico e turistico" (Bratuń, 2014, p. 28). Teofila Morawska (1738-1807) proveniva da illustre famiglia di magnati che si stabilì a Niasviz. Si interessava di lingue straniere, souvenir antichi e collezionismo. 
Negli anni 1773-1774 viaggiò in terre tedesche, francesi e italiane (Kowalczyk, 2005, p. 79, 2019, pp. 55-56; Kurządkowska, 2015, pp. 185-193; Wrześniak, 2013, pp. 123-124). Katarzyna Plater (1748-1832) Veniva da una una nobile famiglia con una tenuta a Sosnowica. Fu un'attenta osservatrice delle nuove tendenze della cultura e dell'arte. Nel 1785 iniziò una spedizione in giro per l'Europa (Mucha, 2011, pp. 133-134; Kowalczyk, 2019, pp. 66-67). Entrambe le nobildonne tenevano appunti regolari durante i loro viaggi. Nei diari si parla della permanenza negli importanti centri di pellegrinaggio del Veneto. Descrivevano principalmente l'architettura delle chiese di Venezia e Padova, in cui interno ammirarono tra l'altro, costosi altari, lapidi, sculture e dipinti di artisti famosi (cf. Kowalczyk, 2014, p. 326; Roćko, 2014, p. 138).

Anche gli scritti a forma di guida, quelli di Kazimierz Kognowicki e Paweł Ksawery Brzostowski meritano attenzione. Andarono in Italia per completare la loro istruzione e conoscere famosi centri di scienza e religione. Tenevano appunti quotidiani sotto forma di itinerari. Al ritorno in patria, fecero le modifiche dei testi e li hanno pubblicarono per i futuri viaggiatori. Kazimierz Kognowicki (1746-1825) era un nobile dello stemma di Dąbrowa, un ecclesiastico e uno storico. Nel 1764 entrò nell'ordine dei Gesuiti e, dopo lo scioglimento della congregazione, fu insegnante presso la scuola riformata di Grodno. Nel 1782 viaggiò per l'Italia (Chachulski, 2014, pp. 359-360; Sajkowski, 1973, p. 195; Kowalczyk, 2005, pp. 7475; Wrześniak 2010b, p. 174). Paweł Ksawery Brzostowski (1739-1827) discendente da una nobile famiglia dello stemma Strzemię. Nel $1755 \mathrm{fu}$ ordinato sacerdote e divenne canonico di Vilnius. Negli anni 1758-1762 studiò teologia a Roma, e al suo ritorno visitò l'Italia (Ślusarska, 2014, p. 335; Wrześniak, 2013, p. 97). Entrambi i pellegrini lasciarono descrizioni della Basilica di S. Marco a Venezia. Hanno ammirato la struttura e arredi di questo tempio. Le basiliche di Padova documentò Kazimierz Kognowicki. Era compiaciuto dalle loro dimensioni e ricchezza, nonché da un prezioso deposito, in particolare reliquie e polonica.

\section{Esempi e schemi della descrizione degli edifici sacri}

Analizzando le descrizioni contenute nei racconti pellegrini del XVIII secolo, si possono notare alcune definizioni e idee ricorrenti sui santuari italiani. I resoconti dei viaggiatori menzionavano spesso le dimensioni, le forme e le decorazioni dei templi. Riportavano meticolosamente descrizioni di materiali di pregio (oro, argento, marmo, alabastro, diaspro). Indicarono la posizione del deposito e ne ammirarono la grandezza e lo splendore. A volte presentavano l'oggetto più famoso della collezione della chiesa. Un elemento costante della narrazione era il rispetto per la santità e la ricchezza. Pertanto, gli autori delle descrizioni utilizzavano convenzioni presenti in letteratura. Queste norme e motivazioni diedero ai viandanti una percezione di santuari veneziani e padovani attraverso la formazione intellettuale e culturale (Dziechcińska, 1999, p. 73). 
I polacchi hanno acquisito conoscenze sulla formazione dei testi durante l'istruzione scolastica. Hanno preso le loro regole e i diagrammi già pronti dai libri di testo di retorica (Dziechcińska, 1999, p. 68). Contenevano le opinioni di antichi studiosi e retori (Aristotele, Cicerone, Quintiliano) su ekphrasis, cioè descrizioni di opere d'arte (architettura, pittura, scultura). II teoretici della dell'arte consigliavano di lodare e analizzare l'oggetto secondo il principio della visualizzazione (evidentia). Il rapporto doveva contenere un'immagine visiva che influisse sul senso della vista del destinatario-lettore. Importante era anche il principio dell'enumerazione dei singoli elementi di un oggetto artistico (enumeratio). Commenti simili sono stati fatti nei trattati di poetica. Nel suo trattato Sulla poesia perfetta, Maciej Kazimierz Sarbiewski spiegò come costruire una corretta descrizione del manufatto nell'epica, raccomando di caratterizzare i singoli componenti - forma, colore, materiale e applicazione nella parte descrittiva (Krzywy, 2013, p. 130).

Va notato che gli esempi delle ekphrasis offrivano principalmente poesie antiche. Già in opere antiche apparivano immagini di edifici, sia reali che immaginari. Secondo Małgorzata Czermińska (2005), "i temi architettonici, come una casa - e specialmente la casa di una divinità o di un sovrano terreno, cioè un tempio e un palazzo - apparivano come parte del mondo presentato dalla letteratura" (ibidem, p. 113). Le descrizioni convenzionali includevano informazioni sulla dimensione e la forma degli edifici, dettagli architettonici e materiali costosi. Secondo questo canone, Omero nel'Odissea raffigurava la residenza del sovrano di Alkinoos su Scheria, Virgilio nel'Eneide analogamente descrisse il tempio di Giunone a Cartagine, e Ovidio nelle Metamorfosi mostrò il palazzo di Elio. Publio Stazio nelle Silvae illustra seguenti ipotesi architettoniche, come: le ville di Manilio Wopisek a Tibur vicino a Roma e di Pollius Felix a Surrentum sul Golfo di Napoli, come pure il santuario di Ercole a Surrentum. Le analoghe ekphrasis furono preparate dai successivi poeti chansons de geste, Alighieri Dante nella Divina Commedia e Torquato Tasso nella Gerusalemme liberata. Le immagini dell'edificio sono apparse anche nella letteratura polacca del Rinascimento e del Barocco. Hanno lasciato immagini poetiche di edifici rappresentativi, tra gli altri: autore di Oblężenie Jasnej Góry Częstochowskiej, Samuel Twardowski nella Nadobna Paskwilina, Pałac Leszczyńskiego e Przeważna legacya Krzysztofa Zbaraskiego, Samuel Leszczyński nel Classicum nieśmiertelnej sławy, Augustyn Kołudzki nel Tron ojczyzny (Krzywy, 2013, pp. 121-134; Pfeiffer, 2001, pp. 64-75).

Anche la Sacra Scrittura forniva enunciati pronti. Bisogna menzionare quattro brani biblici, i quali: l'ekphrasis della Tenda di convegno dal libro dell'Esodo (Es 26, 1-37), l'immagine del Tempio di Salomone nel Primo Libro dei Re (1Re 6: 1-38), la visione del tempio dal Libro di Ezechiele (Ez 43, 1-12) e l'immagine della Nuova Gerusalemme dal Libro dell'Apocalisse. Giovanni (Ap 21, 1-27) (cf. Czermińska, 2005, s. 113; Kobielus, 1989, s. 97 103). Roman Krzywy (2013) spiega che "queste descrizioni forniscono le dimensioni dei templi, enumerano i loro componenti e prestano attenzione ai materiali nobili utilizzati nella 
costruzione" (ibidem, p. 136). È facile notare che il clero ei pellegrini polacchi nel XVIII secolo mostrarono interesse per componenti simili disegnando descrizioni dei santuari che videro. Nei loro diari annotavano spesso il numero delle cappelle, le dimensioni degli oggetti e dei loro ornamenti. Gli autori dei rapporti citavano anche oggetti legati alla Terra Santa. Per esempio, Krzysztof Zawisza e Symforian Arakiełowicz donarono le colonne del Tempio di Salomone collocate nella Basilica di S. Marco a Venezia (cf. Zawisza, 1862, p. 80; Arakiełowicz, 2016, p. 75). Remigiusz Zawadzki mise l'attenzione sulle stesse cose sacre, annotando: "nel portico della chiesa mostrano quattro colonne di marmo nero e dicono che provengono dalla chiesa di Salomone" (cit. Zawadzki, 2014, p. 104).

Anche i trattati apodemici e gli scritti enciclopedici furono di grande importanza nello sviluppo di metodi per descrivere i templi. Questi testi fornivano informazioni sui santuari e sugli oggetti di importanza per la religione cristiana che vi erano raccolti. Secondo Roman Krzywy, queste opere contenevano "oltre a considerazioni generali sulla motivazione dei viaggi e consigli pratici (...) anche suggerimenti su quali informazioni ogni viaggiatore dovrebbe inserire nei suoi documenti" (2013, p. 86). Per esempio, Jan Drews nel compendio geografico Wybór królestw albo krótkie opisanie czterech stron świata ha presentato le città italiane, tra cui Venezia. Ha anche notato molte peculiarità che dovrebbero deliziare il pellegrino (Kowalczyk, 2005, pp. 36-37). Benedykt Chmielowski in Nowe Ateny prestava attenzione anche alle basiliche italiane (Kowalczyk, 2005, pp. 39-40). Un ruolo altrettanto importante è stato svolto dalle guide e dai cataloghi dei centri di pellegrinaggio. Presentavano elenchi di oggetti di valore custoditi nei sotterranei delle chiese, come reliquie e insegne di incoronazione o opere d'arte. A volte contenevano commenti sui miracoli del santo patrono di un dato santuario (Mączak, 1998, pp. 64-65).

Nel contesto di queste considerazioni vale la pena ricordare il diario di Juwenalis Charkiewicz. Durante la spedizione, il sacerdote ha preso appunti, che ha integrato con i dati dei giornali geografici dopo il suo ritorno al convento di Vilnius. Secondo esiti delle ricerche di Bogdan Rok questo frate riferì molte notizie sull'Italia in una guida Świat we wszystkich swoich częściach di Władysław Łubieński (cf. Rok, 1998, pp. 5-10; Kowalczyk, 2005, p. 83). L'autore del rapporto ha ammesso di aver utilizzato i "manoscritti di viaggio" a sua disposizione (cit. Charkiewicz, 1998, p. 179). In un resoconto del suo soggiorno a Venezia, annotò: "ricorderò un po' l'ubicazione di questa città, lasciando i governi di questa Repubblica, prendendo la strada e altre cose che non mi appartengono, e nei libri stampati geografici e politici tutti possono trovare il latino" (cit. Charkiewicz, 1998, p. 188). August Moszyński, d'altra parte, dichiarò nel diario di aver registrato impressioni personali dei monumenti che aveva visto, sebbene avesse familiarità con le guide di autori come: JosephJérôme Lalande e Charles Nicolas Cochin, oppure Ristretto delle cose più notabili della città di Firenze Raffaello del Bruno (cf. Moszyński, 1970, p. 162; Wrześniak, 2013, p. 135). 
La narrativa, un romanzo sentimentale, d'avventura e di viaggio, particolarmente popolare all'epoca, era una diversa fonte di schemi (cf. Dziechcińska, 1999, p. 61). I pellegrini colti ricorrevano spesso a mezzi stilistici tipici del linguaggio artistico. Perciò, Kazimierz Kognowicki costruì la sua descrizione di Venezia su un'antitesi. Nel suo reportage di viaggio scrisse così: "qui tutto è interessante: Le fonti d'acqua senza sorgenti, Città senza terra, Fortezza senza argini, abbondanza senza fertilità, consegna di tutto senza cavalli, umanità senza politica, la sepoltura di morti senza una bara ..." (cit. Kognowicki, 1783, p. 59). Anche studiosi e teorici d'arte hanno espandevano le loro descrizioni usando frasi insolite. Aggiungevano commenti personali, divagazioni ed esperienze derivanti dagli oggetti che avevano visto (Dziechcińska, 2003, pp. 58-59). August Moszyński nella presentazione del tesoro del santuario di S. Antonio a Padova introdusse l'ironia. Nel suo diario annotò: "Da quando viaggio, non ho visto niente di simile. Abbiamo dovuto inginocchiarci e recitare le preghiere prima che le porte del tabernacolo fossero aperte. Il sacerdote, con un bastone in mano, stava toccando le reliquie, e un altro le nominò secondo il catalogo che aveva in mano. Mi è sembrato di aver sentito Diego (nella persona di) fratello Mateusz, enumerare i suoi pellegrinaggi" (cit. Moszyński, 1970, p. 561).

\section{Viaggiatori polacchi sui tesori dell'arte sacra}

I polacchi che hanno attraversato l'Italia nel XVIII secolo di solito includevano un elenco di oggetti ammirati nelle pagine dei loro diari e diari. Nei loro resoconti di visita a Venezia, menzionarono principalmente la Basilica di S. Marco. Consideravano questo tempio un simbolo della città. Felicjan Piaskowski annotava nel suo diario: "Tra le chiese, il primo è S. Marco famoso per l'antichità e preda di Costantinopoli" (cit. Piaskowski, 1865, p. 30). Stanisław Staszic invece, afferma concisamente nel suo diario: "Ho visto tutto nel palazzo ducale, nella chiesa di S. Marco, nelle chiese di S. Giovanni e S. Paolo..." (cit. Staszic, 1931, p. 44). I vaggiatori polacchi del loro soggiorno a Padova citarono principalmente il tempio dedicato a S. Antonio, e poi la Basilica di S. Giustina. Stanisław Staszic notò che in quella città "ci sono molti e grandissimi edifici monastici, monasteri e nuove, grandissime chiese. Come la chiesa di S. Antonio, S. Giustina..." (cit. Staszic, 1931, p. 45).

I pellegrini settecenteschi scrissero anche rappresentazioni più estese di famose basiliche nei loro resoconti di visita a Venezia e Padova. Gli scrittori, seguendo la tradizione descrittiva degli edifici sacri, iniziavano le loro dichiarazioni mostrando l'architettura delle chiese. Hanno fornito la loro disposizione spaziale, numero di cupole o decorazioni esterne. Remigiusz Zawadzki nel diario sul tempio di S. Marco a Venezia ha dichiarato: "Questa chiesa è grandiosa e più preziosa che bella. È costruita su una pianta a croce, interamente in pietra squadrata" (cit. Zawadzki, 2014, p. 104). Maciej Borkowski ha caratterizzato il santuario veneziano come un "grande tesoro, con cinque cupole, coperte di lamina di rame, 
con una bella facciata" (cit. Borkowski, 1995, p. 105). Paweł Brzostowski scrisse nella sua guida: "Chiesa di S. Marco, Architettura Gotica, quattro belle colonne di alabastro" (cit. Brzostowski, 1811, p. 35). Stanisław Kleczewski sull'edificio dedicato a S. Antoni a Padova, ha informato: "Ha cinque cupole e due torri, coperte di piombo" (cit. Kleczewski, 2016, p. $358)$, ha inoltre menzionato che la Basilica di S. Giustina "è costruita come un teatro, in modo che tu possa vedere l'intera chiesa da ogni angolazione" (cit. Kleczewski, 2016, p. 358). Juwenalis Charkiewicz scrisse: "Chiesa di S. Antonio ai Conventuali, bello e ricco, mi sembra sette cupole ricoperte di piombo. La Chiesa èsu una pianta a croce" (cit. Charkiewicz, 1998, p. 194), e poi ha aggiunge: "La Chiesa di S. Giustina e il monastero sotto la giurisdizione di PP Benedettini (...) magnifico, grande sia per la struttura e sia per i marmi" (cit. Charkiewicz, 1998, p. 194).

I viaggiatori polacchi includevano nelle loro note anche una valutazione dei templi della regione Veneto. I creatori di ekphrasis spesso si meravigliavano delle dimensioni, dell'antichità e della ricchezza delle chiese. Krzysztof Zawisza accenna brevemente alle caratteristiche di S. Marco a Venezia, dicendo: "antichità molto grande, pura rarità" (cit. Zawisza, 1862, p. 80). Anche Teofila Morawska valutò questo edificio come "il più costoso, molto antico e interessante" (cit. Morawska, 2002, p. 124). Kazimierz Kognowicki scrisse in modo simile: "La chiesa di S. Marco è la più antica e la più costosa" (cit. Kognowicki, 1783, p. 47). Felicjan Piaskowski affermò sulle chiese di Padova che "la chiesa di S. Giustina, che per il suo splendore non si vergognerebbe di splendere anche nel mezzo di Roma; e la chiesa di S. Antonio, con la sua antichità suscita più attenzione di quanto non volge gli occhi" (cit. Piaskowski, 1865, p. 28). Symforian Arakiełowicz, che ha visitato Padova con altri monaci, scrisse così nel suo diario: "Eravamo con i Padri Benedettini quel giorno a S. Giustina, dove c'è una chiesa molto spaziosa, simile anche alla [chiesa] di S. Antonio ha cinque cupole, ma molto più splendide e magnifiche" (cit. Arakiełowicz, 2016, p. 80). Allo stesso modo, per August Moszyński e Stanisław Staszic, questo edificio sacro era il più grande e il più bello di Padova (cf. Moszyński, 1970, p. 569; Staszic, 1931, p. 46).

I viaggiatori del Settecento prestavano particolare attenzione all'interno delle chiese. Gli autori dei testi hanno riconosciuto la tecnica di realizzazione degli ornamenti e il tipo di materiale. Krzysztof Zawisza nel suo diario sul pavimento della Basilica di S. Marco a Venezia riferì che era fatta di "mosaici squisiti" (cit. Zawisza, 1862, p. 80). Stanisław Kleczewski, invece, ha lasciato una descrizione più ampia della decorazione degli interni di questo edificio, citando minerali preziosi (oro, marmi policromi e vetri, ambra) e caratterizzando le rappresentazioni sul pavimento e sulle pareti (cit. Kleczewski, 2016, p. 238). Nel suo diario di viaggio Katarzyna Plater sul tempio veneziano scrive così: "Inconcepibile quanto fosse ricca. L'intero edificio, sia all'interno che all'esterno, era realizzato in porfido, granito, marmo, bronzo e alabastro. Il numero di colonne che si erigevano era impressionante. All'interno, abbiamo camminato solo su pietre preziose, 
eravamo circondati solo da oggetti meravigliosi" (cit. Plater, 2013, p. 78). I pellegrini ammiravano anche la ricca decorazione dei templi padovani. Teofila Morawska ha riferito che la chiesa in onore di S. Antonio era "sufficientemente decorato con dipinti e marmi" (cit. Morawska, 2002, p. 134). Maciej Borkowski annotò nel suo diario che l'edificio era "molto costoso all'interno" (cit. Borkowski, 1995, p. 108). Più avanti sull'edificio di S. Giustna ha ricordato: "L'intera chiesa con un soffitto dorato e un pavimento di marmo decorativo" (cit. Borkowski, 1995, p. 109).

Le descrizioni dei visitatori provenienti dalla Polonia documentano anche importanti elementi dell'arredo del tempio, come gli altari, notando le loro dimensioni e decorazioni. Krzysztof Zawisza ha ammirato le colonne di alabastro che fiancheggiano l'altare del Santissimo Sacramento nella Basilica di S. Marco a Venezia (cf. Zawisza, 1862, p. 80). Tra le attrezzature all'interno del tempio, Juwenalis Charkiewicz ha citato: "ciborio di alabastro" (cit. Charkiewicz, 1998, p. 190). Anche Maciej Borkowski ha richiamato l'attenzione su questa costruzione, affermando: "Dietro l'altare al ciborio, due grandi colonne di alabastro, stranamente trasparenti, due di marmo africano" (cit. Borkowski, 1995, p. 105). Stanisław Kleczewski dal suo soggiorno nella Basilica di S. Antonio a Padova, annotava nel suo diario che "tutti i paliotti sono ricoperti di mosaici. Spicca di più quello, sul quale da lontano puoi vedere il cranio formato di una testa umana con ossa e da vicino - vari strumenti musicali" (cit. Kleczewski, 2016, p. 358). Symforian Arakiełowicz, descrivendo l'aspetto della basilica dedicata a S. Giustina, ha informato: "i paliotti degli altari sono rivestiti con pietre di vari colori, che a malapena persone, uccelli e fiori potrebbero essere presentati meglio da un pittore con un pennello" (cit. Arakiełowicz, 2016, p. 80). In un diario sull'interno di questo tempio, Maciej Borkowski scrisse: "Tutti gli altari laterali nelle cappelle, di cui ce ne sono 14, fatte di marmo costoso, dietro sbarre di ferro con cornice in ottone hanno le opere d'arte" (cit. Borkowski, 1995, p. 109).

Nelle relazioni sulle visite nei santuari italiani si commemorano anche sculture, dipinti ed epitaffi visti nelle basiliche. Katarzyna Plater nella descrizione del tempio dedicato a S. Antonio a Padova, concludeva: "Tutta la chiesa era ornata di figure poste sopra le lapidi" (cit. Plater, 2013, p. 93). Stanisław Staszic scrisse allo stesso modo "ci sono molte belle lapidi nella chiesa" (cit. Staszic, 1931, p. 47). A loro volta, nella seconda celebre basilica padovana, i viaggiatori ammiravano soprattutto le immagini dei santi. Krzysztof Zawisza ha detto: "La chiesa di S. Giustina PP. Bernardini piuttosto magnifici, dipinti particolari negli altari" (cit. Zawisza, 1862, p. 84). Teofila Morawska, invece, cita l'opera Martirio di S. Giustina, che vide nel coro del tempio. Nel suo diario scrisse: "L'immagine di questa santa [nel] grande altare, dove giace anche il suo corpo, dipinto con la stessa mano anteriore di Peter Tycius" (cit. Morawska, 2002, p. 134). Il viaggiatore, però, confuse l'autore di quest'opera, che fu Paolo Veronese. August Moszyński, visitando la Basilica di S. Giustina, nella sua relazione annota: "tutti i viaggiatori, e io (...) notai il dipinto nell'abside della navata. Il dipinto raffigura il 
martirio di S. Giustina di Paolo Veronese" (cit. Moszyński, 1970, p. 569). Notò anche che: "le colonne dorate che accompagnano il dipinto non gli sono benefici" (cit. Moszyński, 1970, p. $569)$.

I polacchi menzionavano spesso nei loro testi oggetti riferiti alla loro patria. Principalmente furono interessati alle tombe dei loro connazionali a S. Antonio a Padova. Stanisław Kleczewski nel suo diario disse così: "Ci sono numerosi epitaffi di nobili polacchi, specialmente intorno all'altare di S. Stanislao, vescovo e martire" (cit. Kleczewski, 2016, p. 358). Teofila Morawska affermò sinteticamente: "in questa chiesa giacciono i corpi di alcuni polacchi. Pietra tombale di Kretkowski - il castellano di Gniezno" (cit. Morawska, 2002, p. 134). Maciej Borkowski ricordò: "in questa chiesa ci sono lapidi molti signori, anche polacchi, come: Ossoliński, Krzysztof Szembek, Mniński" (cit. Borkowski, 1995, p. 109). Kazimierz Kognowicki ha già accuratamente indicato le polonica nella Basilica di Padova, annotando: "Dalla porta alla mano destra, l'altare della Polonia, dove Krzysztof e J. Kazimierz Sapieha hanno lapidi. Qui fu sepolto anche Giovanni Albrecht, cardinale, vescovo di Cracovia e fratello di Ladislao IV. Re di Polonia" (cit. Kognowicki, 1783, p. 71). Stanisław Staszic, invece, nel diario rivelava "nella stessa chiesa, S. Antoni, ho visto la tomba dei polacchi: Ossoliński, Ponętowski e Miński, morti nelle scuole lì" (cit. Staszic, 1931, p. 48).

I viaggiatori polacchi nelle descrizioni degli edifici sacri citavano altresì il luogo destinato alla raccolta di oggetti di valore. Krzysztof Zawisza, indicando gli oggetti di valore situati nella Basilica di S. Marco a Venezia, disse: "La pietra di marmo nel muro, su cui S. Giovanni fu decapitato" (cit. Zawisza, 1862, p. 80). A sua volta, Maciej Borkowski ha presentato precisamente la posizione di questa cosa reliquia, annotando: "Nel portico sul lato destro della chiesa, una cappella significativa, in cui sul lato del portico c'è una pietra su cui la testa di S. Giovanni Battista fu tagliato, bianco, pesantemente macchiato di sangue" (cit. Borkowski, 1995, p. 105). Pellegrini nei messaggi sulla Basilica di S. Antonio di Padova, si informavano solitamente della cappella detta del tesoro. Remigiusz Zawadzki ha affermato che "Vi è conservata una lingua benedetta intatta con la mascella di S. Antonio" (cit. Zawadzki, 2014, p. 108). Nella guida, Kazimierz Kognowicki rivelò che vi erano molte reliquie in quel luogo, e "tra queste l'intera lingua di S. Antoni" (cit. Kognowicki, 1783, p. 71). Gli autori dei testi hanno anche richiamato l'attenzione sul metodo di conservazione delle reliquie nel tempio di S. Giustina a Padova. Symforian Arakiełowicz, nel suo resoconto sulla permanenza in questa basilica, scrisse: "Il corpo di S. Giustina è custodito all'interno del grande altare" (cit. Arakiełowicz, 2016, p. 80). Stanisław Kleczewski e Maciej Borkowski, oltre alla posizione delle spoglie del santo patrono del santuario, hanno indicato la posizione di altre reliquie, tra cui S. Luca e S. Matteo in sarcofagi separati nella cappella laterale (cf. Kleczewski, 2016, p. 358; Borkowski, 1995, p. 109).

Quelli che prendevano appunti caratterizzavano anche l'interno delle stanze dove erano conservate le reliquie. I viandanti ammiravano principalmente le decorazioni della 
cappella con la tomba di S. Antonio nella basilica a lui dedicata a Padova. Hanno visto il tipo di materiale (marmo, oro), così come un gran numero di candele. Felicjan Piaskowski affermò nel suo diario che questo luogo sacro "ha un notevole ornamento, non solo con lappe di varie dimensioni, medie, oltre quaranta delle quali sono sempre accese, ma anche con deliziose sculture di marmo bianco" (cit. Piaskowski, 1865, pp. 28-29). Juwenalis Charkiewicz ha scritto: "nella cappella della croce giace il corpo di S. Antonio operatore di miracoli, nell'altare in una bara di marmo nero" (cit. Charkiewicz, 1998, p. 194). Teofila Morawska ricordava similmente: "La cappella dove si trovava la tomba di S. Antoni, il più magnifico, a parte molto argento dietro l'altare, le scene di miracoli di questo santo sono realizzati in marmo stranamente dai migliori artigiani" (cit. Morawska, 2002, p. 134). Katarzyna Plater, invece, ha annunciato: "La cappella del santo era notevole per la ricchezza dell'arredamento. Era fatto di marmo e tutti i capolavori che lo decoravano avevano la forma di bassorilievi che emergevano dallo scalpello di Sansovino" (cit. Plater, 2013, p. 93).

Anche i pellegrini del XVIII secolo lasciarono ampi cataloghi di raccolte ecclesiastiche, nei loro resoconti sulle visite nei santuari italiani. Gli autori dei testi enumeravano meticolosamente ogetti di valore visti. Felicjan Piaskowski, descrivendo il contenuto del tesoro della Basilica di S. Marco a Venezia, disse: "qui tengono una mitria, con la quale si coronava i principi e altri gioielli, ma questo luogo è più ricco di reliquie che di altre ricchezze, che si vedono tanto" (cit. Piaskowski, 1865, p. 31), e poi elencò oggetti di valore, come reliquie, oggetti leggendari e ex voto di monarchi (cf. Piaskowski, 1865, p. 31). Symforian Arakiełowicz si compiaceva per la tesoriera della chiesa di S. Antonio a Padova. Il monaco annota nel suo diario di aver visto "la sacrestia, il luogo dove sono conservate le sante reliquie" (cit. Arakiełowicz, 2016, p. 79) e vi affisso un elenco di cose sante (cf. Arakiełowicz, 2016, pp. 79-80). In modo simile nell'inventario, Maciej Borkowski menziona la cappella con la tomba di S. Antonio nel Santuario di Padova. Nel diario il sacerdote affermava che era "tutto in marmo di infinita ricchezza, poiché conteneva 50 lampade d'argento, una delle quali era d'oro puro, 4 angeli fusi in argento, 3 candelieri con figure dello stesso tipo, candelieri, cuscini per il messale, una bara in cui il cadavere trasformò in polvere bianca, argento, paliotto di marmo verde con le venature d'oro" (cit. Borkowski, 1995, pp. 108-109).

\section{Conclusioni}

Concludendo le riflessioni sulla descrizione dei tesori dell'arte sacra a Venezia e a Padova, si può notare che santuari del Veneto furono frequentatissimi nel Settecento. Sono diventati una tappa importante nei viaggi italiani, tra cui: pellegrinaggi, spedizioni diplomatiche e scientifiche, viaggi turistici. Hanno attratto con magnifici templi, in particolare la Basilica di S. Marco a Venezia, oltre a due basiliche a Padova: S. Antonio e S. 
Giustina. Per i viaggiatori polacchi del XVIII secolo, questi edifici erano spazi speciali. Sono stati percepiti come capolavori delle città italiane, luoghi sacri, e al tempo stesso ipotesi architettoniche plasmate secondo le regole dell'arte. Secondo i viandanti di quel tempo, erano usati per raccogliere, conservare ed esporre oggetti di valore: reliquie, opere d'arte e polonica.

L'analisi delle descrizioni contenute nei documenti pellegrini settecenteschi mostra che vi erano tendenze costanti nella presentazione dei santuari italiani. Scrivendo resoconti sulle visite ai centri urbani si parlava di edifici famosi come le basiliche. Un gruppo separato sono le ekphrasis dei templi. Tali descrizioni comprendono, prima di tutto, riferimenti alla forma (vista dall'esterno, dettagli architettonici e materiali) e alla natura dell'edificio (dimensioni, ricchezza, antichità), e poi informazioni dettagliate: l'arredamento (tecnica di produzione, materiale, contenuto dei dipinti) e altre attrezzature (altari, epitaffi, sculture e dipinti, polonica). Il terzo tipo di note sono i cataloghi delle raccolte ecclesiastiche. Gli autori di solito hanno rivelato la posizione del deposito. Ammirarono anche l'aspetto delle cappelle con le reliquie. A volte includevano nei loro appunti un elenco di oggetti di valore raccolti nel tesoro della chiesa. A loro piaceva ricordare oggetti grandi, rari e costosi. Va aggiunto che gli amanti e gli intenditori della creatività artistica hanno condiviso le loro osservazioni e opinioni personali, nonché giudizi estetici nelle loro relazioni. Le descrizioni dei tesori dell'arte sacra veneziana e padovana costituiscono quindi un fenomeno letterario e culturale peculiare del Settecento.

Tradotto da: PhD Julia Krauze, https:/ / orcid.org/0000-0002-9536-715X

\section{Bibliografia:}

Abramowska, J. (1978). Peregrynacja, (w:) M. Głowiński, A. Okopień-Sławińska (red.), Przestrzeń i literatura, 121-158, Wrocław: Zakład Narodowy im. Ossolińskich.

Arakiełowicz, S. (2016). Itinerarium Romanum (1723). B. Rok (oprac.), D. Piwowarczyk (tłum.), Podróż Rzymska (1723), Kraków-Wrocław: Księgarnia Akademicka.

Backvis, C. (1975). Jak w XVI wieku Polacy widzieli Włochy i Włochów, (w:) A. Biernacki (red.), Szkice o kulturze staropolskiej, 687-769, Warszawa: PIW.

Barycz, H. (1965). Spojrzenia w przeszłość polsko-włoską, Wrocław: Zakład Narodowy im. Ossolińskich.

Biliński, B. (1968). Viaggiatori polacchi a Venezia nei secoli XVII-XIX (saggio preliminare: esempi ed osservazioni generali), (w:) L. Cini (red.), Venezia e la Polonia nei secoli dal XVII al XIX, 341-417, Venezia-Roma: Istituto Per La Collaborazione Culturale.

Borkowski, M. (1995). Diariusz wojażu rzymskiego, M. Grzybowski (oprac.), Warszawskie Studia Teologiczne, t. 5, 95-146. 
Brahmer, M. (1939). Z dziejów włosko-polskich stosunków kulturalnych. Studia i materiaty, Warszawa: Towarzystwo Literackie im. A. Mickiewicza.

Brahmer, M. (1980). Powinowactwa polsko-włoskie. Z dziejów wzajemnych stosunków kulturalnych, Warszawa: PWN.

Bratuń, M. (2002). "Ten wykwintny, wykształcony Europejczyk". Zagraniczne studia i podróże edukacyjne Michała Jerzego Wandalina Mniszcha w latach 1762-1768, Opole: Wydawnictwo UO.

Bratuń, M. (2014). Grand Tour: narodziny - rozwój - zmierzch, (w:) A. Roćko (red.), Polski Grand Tour XVIII i początkach XIX wieku, 19-30, Warszawa: Muzeum Pałacu Króla Jana III w Wilanowie.

Brzostowski, P. K. (1811). Kościoły, malowania znaczniejsze w Rzymie, w niektórych miastach włoskich, niemieckich, francuskich i polskich podtug opisania innych ode mnie uważane P. H. B. R. W. X. L. K. O. P., Wilno: Nakładem i drukiem Iózefa Zawadzkiego.

Chachaj, M. (1998). Związki kulturalne Sieny i Polski do końca XVIII wieku. Staropolscy studenci i podróżnicy w Sienie. Sieneńczycy i ich dzieła w Polsce, Lublin: Wydawnictwo UMCS.

Chachaj, M. (2001). Zapomniana podróż zagraniczna (1717 - 1720) Felicjana Piaskowskiego na tle szlacheckich peregrynacji czasów saskich, (w:) , J. Muszyńska (red.), Rzeczpospolita w dobie wielkiej wojny pótnocnej, 343-360, Kielce: Wydawnictwo AŚ.

Chachulski, T. (2014). Kazimierza Kognowickiego relacja z rzymskiej podróży, (w:) A. Roćko (red.), Polski Grand Tour XVIII i poczatkach XIX wieku, 357-373, Warszawa: Muzeum Pałacu Króla Jana III w Wilanowie.

Charkiewicz, J. (1998). Dyjariusz podróży hiszpańskiej z Wilna do miasta Walencyi na kapitute jeneralna zakonu mniejszych braci św. Franciszka, to jest bernardynów, odprawionej w roku 1768, B. Rok (oprac.), Wrocław: Wydawnictwo UWr.

Cieński, A. (1992). Pamiętniki i autobiografie światowe, Wrocław: Zakład Narodowy im. Ossolińskich.

Czermińska, M. (2000). Autobiograficzny trójkąt, świadectwo, wyznanie i wyzwanie, Kraków: Universitas.

Czermińska, M. (2005). Gotyk i pisarze. Topika opisu katedry, Gdańsk: Słowo / obraz terytoria.

Dziechcińska, H. (1967). Proza staropolska. Problemy gatunków i literackości, Wrocław: PAN.

Dziechcińska, H. (1988). Podróż - jej miejsce w świadomości społecznej, Odrodzenie $i$ Reformacja w Polsce, 33, 27-51.

Dziechcińska, H. (1991). O staropolskich dziennikach podróży, Warszawa: Instytut Badań Literackich PAN.

Dziechcińska, H. (1992). O świadomości urbanistycznej staropolskich peregrynatów, Gdańskie Zeszyty Humanistyczne, 32, 163-187.

Dziechcińska, H. (1993). Miejsce przekazu pamiętnikarskiego w kulturze dawnej Polski, Rocznik Towarzystwa Literackiego imienia Adama Mickiewicza, 28, 3-14. 
Dziechcińska, H. (1999). Pamiętniki czasów saskich. Od sentymentalizmu do sensualizmu, Bydgoszcz: Wydawnictwo Uczelniane Wyższej Szkoły Pedagogicznej.

Dziechcińska, H. (2003). Świat i człowiek w pamiętnikach trzech stuleci: XVI-XVII-XVIII, Warszawa: Instytut Badań Literackich PAN.

Dziechcińska, H. (2011). Dawne dzienniki podróży - dokument „świadomości urbanistycznej", (w:) M. Wrześniak (red.), Iter Italicum. Sztuka i historia / Arte e storia, 269-276, Warszawa: Wydawnictwo UKSW.

Gad, P. (2013). Zagraniczna podróż młodego magnata w świetle diariusza Michała Kazimierza Radziwiłła „Rybeńki”, (w:) B. Mazurkowa (red.), Codzienność i niecodzienność oświeconych. W rezydencji, w podróży $i$ na scenie publicznej, Cz. 2, Katowice: Wydawnictwo UŚ.

Grzybowski, M. (1995). Wstęp, (w:) M. Borkowski, (oprac). Diariusz wojażu rzymskiego, Warszawskie Studia Teologiczne, 5, 95-96.

Grzybowski, S. (1998). Polskie refleksje na temat włoskiego południa (stereotypy, porównania, postulaty), (w:) J. Okoń (red.), Włochy a Polska - wzajemne spojrzenia. Księga referatów międzynarodowej sesji naukowej w Uniwersytecie Łódzkim 15-17 października 1997 roku, 29-38, Łódź: Wydawnictwo UŁ.

Horolets, A. (2012). Dyskursywne konstruowanie podmiotu wiedzącego w wybranych relacjach z podróży, Teksty Drugie, 3 (135), 134-156.

Iwanowska, A. (1990). Polskie rękopiśmienne relacje podróżnicze z epoki saskiej, (w:) H. Dziechcińska (red.), Staropolska kultura rękopisu, 123-154, Warszawa: Instytut Badań Literackich PAN.

Kaczmarek, M. (1962). Specyfika peregrynacji wśród staropolskich form pamiętnikarskich, (w:) W. Dworzaczek (red.), Munera Literaria. Ksiega ku czci prof. R. Pollaka, 95-105, Poznań: PAN.

Kicińska, U. (2014). Pedagogiczny aspekt podróżowania w dawnej Polsce, (w:) Polski Grand Tour XVIII i początkach XIX wieku, A. Roćko (red.), 31-44, Warszawa: Muzeum Pałacu Króla Jana III w Wilanowie.

Kleczewski, S. (2016). Itinerarium Romanum (1750). Podróż Rzymska (1750), M. Chachaj, B. Rok (oprac.), Kraków-Wrocław: Księgarnia Akademicka.

Kobielus, S. (1989). Niebiańska Jerozolima. Od sacrum miejsca do sacrum modelu, Warszawa: Wydawnictwo Apostolicum.

Kognowicki, K. (1783). Droga rzymska z nawrotem do swojej ojczyzny nie bez gościńca nazad powróconego Xiędza Kazimierza Kognowickiego, nauk wyzwolonych i filozofii doktora, Warszawa: Drukarnia J. K. M. u S. Krzyża, from: https://www.wbc.poznan.pl/dlibra/publication/96731/edition/108510/content, (access: 01.12.2021). 
Kostkiewiczowa, T. (1988). L'Italie vue par des Polonais éclairés. Relation des voyages de Stanisław Kostka Potocki et d’Augus Moszyński, (w:) E. Kanceff, R. Lewański (red.), Viaggiatori polacchi in Italia, 203-216, Genève: Slatkine.

Kot, S. (1987). Wenecja w oczach Polaków na przestrzeni dziejów, (w:) , S. Kot (red.), Polska złotego wieku a Europa: studia i szkice, 307-322, Warszawa: PIW.

Kowalczyk, M. E. (2003). O Kazimierzu Symforianie Arakiełowiczu i jego łacińskim rękopisie podróży do Rzymu z pierwszej połowy XVIII wieku, (w:) K. Matwijowski, B. Rok (red.), Studia z dziejów XVII i XVIII wieku, 137-151, Wrocław: Instytut Historyczny UWr.

Kowalczyk, M.E. (2004). Górskie krajobrazy Włoch w polskim piśmiennictwie geograficznym i podróżniczym XVIII wieku, (w:) B. Rok, F. Wolański (red.), Staropolski oglą świata. Materiały z konferencji. Wrocław, 23-24 października 2004 r., 279288, Wrocław: Instytut Historyczny UWr.

Kowalczyk, M.E. (2005). Obraz Wtoch w polskim piśmiennictwie geograficznym i podróżniczym osiemnastego wieku, Torun: Adam Marszałek.

Kowalczyk, M.E. (2014). Polki w Wenecji w drugiej połowie XVIII wieku. Zapiski z podróży Teofili z Radziwiłłów Morawskiej i Katarzyny z Sosnowskich Platerowej, Italica Wratislaviensia, 5, 317-337.

Kowalczyk, M. E. (2019). Zagraniczne podróże Polek w epoce oświecenia, Łomianki: LTW.

Krzywy, R. (2013). Wędrówki z Mnemozyne. Studia o topice dawnego podróżopisarstwa, Warszawa: Muzeum Pałacu Króla Jana III w Wilanowie.

Kurządkowska, B. (2015). Rejestr rzeczy mijanych jako przyczynek do wyznań osobistych w relacji z podróży Teofili Morawskiej, Prace Literaturoznawcze, 3, 185-193.

Kurzyński, P. (2016). Percepcja sacrum w relacjach czterech polskich zakonników z 1768 roku, (w:) D. Quirini-Popławska, Ł. Burkiewicz (red.), Sacrum w mieście. Epoka Nowożytna i czasy wspótczesne. Wymiar religijny, kulturalny $i$ społeczny, t. 2, 105-119, Kraków: Wydawnictwo Akademii Ignatianum, WAM.

Kurzyński, P. (2018). Św. Franciszek z Asyżu - włoskie podróże staropolskich reformatów Stanisława Kleczewskiego oraz Remigiusza zawadzkiego do Rzymu w 1750 roku, Wieki Stare i Nowe, 13 (18), 85-114, http:/ / doi.org/10.31261/WSN.2018.1806.

Loret, M. (1929). Polskie pielgrzymstwo naukowe w Rzymie w XVI - XVIII wieku, (w:) M. Loret (red.), Nauka Polska, jej potrzeby, organizacja i rozwój, XI, 131-173, (b. wyd).

Loret, M. (1930). Życie polskie w Rzymie w XVIII wieku, Roma: Scuola Tipografica Pio X.

Łukasiewicz, J. (2021). La Padova di August Fryderyk Moszyński, Italica Wratislaviensia, 12 (1), 123-140, http://dx.doi.org/10.15804/IW.2021.12.1.07.

Mączak, A. (1998). Odkrywanie Europy. Podróże w czasach renesansu i baroku, Gdańsk: Novus Orbis.

Mączak, A. (2001). Peregrynacje, wojaże, turystyka, Warszawa: Książka i Wiedza. 
Morawska, T. (2002). Diariusz podróży europejskiej w latach 1773-1774, B. Rok (oprac.), Wrocław: Wydawnictwo UWr.

Moszyński, A. (1970). Dziennik podróży do Francji i Wtoch Augusta Moszyńskiego architekta JKM Stanisława Augusta Poniatowskiego 1784-1786, B. Zboińska-Daszyńska (oprac.), Kraków: Wydawnictwo Literackie.

Mucha, D. (2011). O wspaniałości włoskiej rzeźby i malarstwa. Wyjątek z dziennika podróży do Italii Katarzyny Platerowej, (w:) M. Wrześniak (red.), Iter Italicum. Sztuka i historia / Arte e storia, 133-171, Warszawa: Wydawnictwo UKSW.

Niedzielski, Cz. (1966). O teoretycznoliterackich tradycjach prozy dokumentarnej: podróż-powieśćreportaż, Torun: PWN.

Norkowska, A. (2020). Miasto polskiego Wieku Świateł. Uwagi o krętej ścieżce powrotu, Pamiętnik Literacki, 1, 5-17, http:/ / doi.org/10.18318/ pl.2020.1.1.

Pfeiffer, B. (2001). Galerie i pałace. Kategoria „ekphrasis” w utworach staropolskich, Pamiętnik Literacki, 2, 61-78.

Piaskowski, F. J. (1865). Pamiętnik Felicyana Junoszy Piaskowskiego podstolego podlaskiego, majora J.K. Mości, począwszy od roku 1690, Lwów: Nakładem K. Jabłońskiego.

Plater, K. (2013). Moja podróż do Wtoch. Dziennik z lat 1785-1786, M.E. Kowalczyk (red.), A. Pikor-Półtorak (tłum.), Łomianki: LTW.

Popiołek, B. (2014). Peregrynacje edukacyjne i poznawcze w źródłach czasów saskich, (w:) A. Roćko (red.), Polski Grand Tour XVIII i początkach XIX wieku, 45-64, Warszawa: Muzeum Pałacu Króla Jana III w Wilanowie.

Roćko, A. (2001). Rzeczpospolita czasów saskich w pamiętniku Krzysztofa Zawiszy-świat wojen, żywiołów, niepokojów, Napis, 7, 313-321.

Roćko, A. (2014). Polski Grand Tour „dam modnych”, (w:) Polski Grand Tour XVIII $i$ początkach XIX wieku, A. Roćko (red.), 131-150, Warszawa: Muzeum Pałacu Króla Jana III w Wilanowie.

Rok, B. (1992). Zagraniczne podróże Polaków w pierwszej połowie XVIII w., Śląski Kwartalnik Historyczny, 1-2, 171-178.

Rok, B. (1998). Juwenalis Charkiewicz i jego podróż po Europie, (w:) J.Charkiewicz J. (red.), Dyjariusz podróży hiszpańskiej z Wilna do miasta Walencyi na kapitułe jeneralna zakonu mniejszych braci św. Franciszka, to jest bernardynów, odprawionej w roku 1768, B. Rok (oprac.), Wrocław: Wydawnictwo UWr.

Rok, B. (2014). Rzym papieski w relacjach Polaków XVIII wieku, (w:) A. Roćko (red.), Polski Grand Tour XVIII i początkach XIX wieku, 313-331, Warszawa: Muzeum Pałacu Króla Jana III w Wilanowie.

Sajkowski, A. (1964). Nad staropolskimi pamiętnikami, Poznań: Wydawnictwo UAM.

Sajkowski, A. (1973). Wtoskie przygody Polaków. Wiek XVI-XVIII, Warszawa: PIW. 
Staszic, S. (1931). Dziennik podróży Stanisława Staszica 1789-1805, C. Leśniewski (z rękopisów wydał), Archiwum do Dziejów Literatury Polskiej, II, t. 2 (ogólnego zbioru XVII), Kraków: Nakładem Polskiej Akademii Umiejętności, from: https://www.pbc.rzeszow.pl/dlibra/publication/5895/edition/5422/content?ref=d esc, (access: 01.12.2021).

Szulakiewicz, W. (2013). Ego-dokumenty i ich znaczenie w badaniach naukowych, Przeglad Badań Edukacyjnych, 16, 1, 65-84.

Ślusarska, M. (2014). Pawła Ksawerego Brzostowskiego przewodnik po zabytkach włoskich, (w:) A. Roćko (red.), Polski Grand Tour XVIII i początkach XIX wieku, 333-356, Warszawa: Muzeum Pałacu Króla Jana III w Wilanowie.

Trzynadlowski, J. (1961). Struktura relacji pamiętnikarskiej, (w:) Z. Czerny i in. (red.), Księga pamiątkowa ku czci Stanistawa Pigonia, 577-583, Kraków: PWN.

Witosz, B. (2007). Gatunki podróżnicze w typologicznym ujęciu genealogii lingwistycznej, (w:) D. Rott (red.), Wokót reportażu podróżniczego, t. 2, 11-29, Katowice: Wydawnictwo UŚ.

Wrześniak, M. (2010a). Roma Santa, Fiorenza Bella. Dzieła sztuki w pamiętnikach polskich podróżników do Włoch w XVI i XVII stuleciu, Warszawa: Wydawnictwo UKSW.

Wrześniak, M. (2010b). Kazimierz Kognowicki o sztuce - Droga rzymska z nawrotem do swoyey oyczyzny nie bez gościńca nazad powróconego, Saeculum Christianum, 1, 173200.

Wrześniak, M. (2010c). Podróż włoska Stanisława Staszica. Kilka słów o guście estetycznym polskiego peregrynanta u schyłku XVIII wieku, Saeculum Christianum, 2, 129-164.

Wrześniak, M. (2010d). Felicjana Junoszy Piaskowskiego Włoch zwiedzanie, Saeculum Christianum, 2, 95-110.

Wrześniak, M. (2011). Italiam! Italiam!, (w:) M. Wrześniak (red.), Iter Italicum. Sztuka i historia/ Arte e storia, 11-105, Warszawa: Wydawnictwo UKSW.

Wrześniak, M. (2012). Miasta włoskie co przedniejsze, czyli o trasie zwiedzania staropolskich podróżników do Italii, (w:) M. Saczyńska, W. Wółkiewicz (red.), Samotrzeć, w kompanii, czy z orszakiem? Spoteczne aspekty podróżowania w średniowieczu i czasach nowożytnych, 283-308, Warszawa: IAE PAN.

Wrześniak, M. (2013), Florencja - muzeum. Miasto i jego sztuka w oczach polskich podróżników, Kraków: Universitas.

Wyrzykowska, M. (2007). XVI-, XVII-, XVIII-wieczne pamiętniki i diariusze polskiej szlachty jako świadectwo mentalności i stanu świadomości artystycznej. Cz. 2: O materiałach, Quart, 4 (6), 3-19.

Wyrzykowska, M. (2012). Percepcja barokowych dzieł sztuki w XVIII wieku w świetle Dziennika podróży do Francji i Włoch w latach 1784-1786 Augusta Moszyńskiego, Quart, 1 (23), 19-43. 
Zawadzki, R. (2014). Diarium itineris Romam (1750). Diariusz podróży do Rzymu (1750), M. Chachaj (oprac.), M. Chachaj, M. Czapińska (tłum.), Kraków-Wrocław: Księgarnia Akademicka.

Zawisza, K. (1862). Pamiętniki Krzysztofa Zawiszy, wojewody mińskiego, J. Bartosiewicz (red.), Warszawa: Nakładem Jana Zawiszy, from: https://www.wbc.poznan.pl/dlibra/showcontent/publication/edition/7409?id=7409\&dirids=1, (access: 01.12.2021).

Zimand, R. (1990). Diarysta Stefan Żeromski, Wrocław: Zakład Narodowy im. Ossolińskich.

Żołądź-Strzelczyk, D. (1998). Podróże edukacyjne w staropolskiej myśli pedagogicznej, Chowanna, 2, 32-46.

Żołądź-Strzelczyk, D. (2011). „Radzę pomknąć go dalej w świat, do Włoch, aby i pierwsze studia przepolerował" - wyjazdy młodych do Italii w staropolskiej teorii i praktyce edukacyjnej, (w:) M. Wrześniak (red.), Iter Italicum. Sztuka i historia / Arte e storia, 277300, Warszawa: UKSW. 